Purdue University

Purdue e-Pubs

\title{
Providing a Meaningful Lab Experience for a Manufacturing Processes Course
}

Kevin Molyet

Trine University, molyetk@trine.edu

Follow this and additional works at: https://docs.lib.purdue.edu/aseeil-insectionconference

Part of the Manufacturing Commons

Molyet, Kevin, "Providing a Meaningful Lab Experience for a Manufacturing Processes Course" (2019). ASEE IL-IN Section Conference. 3 .

https://docs.lib.purdue.edu/aseeil-insectionconference/2019/classroom/3

This document has been made available through Purdue e-Pubs, a service of the Purdue University Libraries. Please contact epubs@purdue.edu for additional information. 


\title{
Providing a Meaningful Lab Experience for a Manufacturing Processes Course
}

\author{
Author: Kevin Molyet \\ Affiliation: Trine University
}

\begin{abstract}
The Manufacturing Processes and Equipment Lab has recently seen a significant increase in the number of students enrolled, leading to difficulty in effectively providing a meaningful lab experience to all of the students. At the same time, it was also desired to give the students a semester long design/build group project that would have to meet typical engineering constraints such as cost, material choice, tolerances, etc. The solution was to have much more involvement from the mechanical engineering lab technician, who then co-taught the lab with a faculty member. The lab technician conducted the weekly lab experiments; developed most of the projects for the students to choose from; and aided the students with practical building advice, running the various shop equipment, and approving and ordering materials/parts that the students requested. The faculty member provided students with design advice; help with their design calculations; graded project reports and presentations, as well as the lab reports; and generally tried to keep the student teams on schedule. Although the logistics of the weekly labs were handled successfully, the final projects were less successful. Many students complained that their projects were too involved and time consuming for a one credit hour lab, or that their projects required knowledge of material from courses they had not yet taken. In order to resolve these issues, in later semesters the final projects were reduced in scope, and the group sizes were increased to better match the difficulty of the assigned projects.
\end{abstract}

\section{Introduction}

The Manufacturing Processes and Equipment (MP\&E) Lab has recently seen a significant increase in the number of students enrolled, leading to difficulty in effectively providing a meaningful lab experience to all of the students. At the same time, it was also desired to give the students a semester long design/build group project that would have to meet typical engineering constraints such as cost, material choice, tolerances, etc. Design projects are already being given to freshman in the Mechanical Engineering Analysis course, as well as a design project in the finite element course Computer-Aided Machine Design normally taken by juniors. However, none of the sophomore level courses has any required semester long project. Since the majority of students take MP\&E Lab during their second year, this course seemed to be appropriate to include a significant design/build project to bridge the gap between the freshman and junior years, in the hopes that the students will become very familiar with the major steps in the design process, as well as learn how to use many of the machines and other tools in the lab, and therefore be more fully prepared for their senior design project.

Hoadley and Rainey [1] discussed a manufacturing processes course where the students are given structured machining activities to produce parts individually and in teams. These activities 
gave the students more awareness of the larger processes involved in engineering, as well as the practical skills needed to later build their senior design projects. Dillon, et. al. [2], reported on the importance of mechanical engineering students learning manufacturing processes, particularly machining. They incorporated a bottle-opener project as an effective way to increase student motivation and learning, which resulted in better performance on the final project and increased confidence in using the machine shop for the senior capstone project. In order to increase student exposure to manufacturing, Ramers [3] enhanced a manufacturing processes course by adding projects that required integrated, multidisciplinary problem solving and engineering management skills; added hands-on projects to existing manufacturing related courses; and enhanced non-manufacturing courses with manufacturing issues and projects. Slifka [4] discussed the use of active learning to engage students in a manufacturing processes course, and included industry-like projects.

\section{Course Description}

Although the typical maximum engineering class size is 30 students, during the spring semester 2017 there were 40 students enrolled in the MP\&E Lab. Two lab sections of 20 students each were created to make the lab more manageable. Students were asked to divide up into groups of two and indicate their top three choices from a list of about sixteen projects. The rankings were then used to assign projects, with most groups receiving one of their top three choices. Four of the projects were assigned to two different groups, but not if they were in the same section; the two groups were expected to work independently of each other.

It was nearly impossible to develop projects that all had the same difficulty level. The projects therefore ranged from relatively simple to more complicated and/or time consuming. Some of the easier projects included building a display case, complete with shelves and power outlets; a grain hopper able to attach to an existing mill; and a scaled-down car frame to demonstrate Ackerman steering. Several projects were completed for the Grounds or Maintenance Departments, such as a storage rack for a tractor cab; a dump trailer used to collect leaves and other debris; and a chop saw table that could easily be extended/retracted. Other projects included a rod bender (Figure 1); a hydraulic aluminum can smasher (Figure 2); providing a fourth axis attachment to the lab's plasma cutter for the purpose of cutting pipe; a cart to make it safer/easier to handle the ladle used in the lab's foundry to pour molten iron; equipment to be used for demonstrating five dynamics principles by instructors of the Dynamics course; an electronics training platform to be used by students as a leaning tool on how to wire an assortment of electrical components; a nerf gun targeting system where one target is knocked down, causing a different target to pop up (Figure 3); a cart for displaying and testing swimming reaction lights; a rocket stove that used a Peltier charger to generate electricity; and a wind turbine tree, which was a structure built to resemble a tree, with leaves that rotate in the wind to generate electricity (Figure 4).

The students were required to go through the main steps of the design process to complete their projects. First they had to meet with the customer to find out their requirements, and then translate those into measurable technical specifications. By the fourth week of the semester, each group needed to submit the first chapter of their final report, which was to include an introduction, customer requirements, technical specifications, and a Gantt chart to display their 
planned tasks and completion dates for the rest of the semester. Each group was also required to give a presentation in front of the class introducing their project and detailing the information in Chapter 1.

The next main step in the design process was concept generation/selection. Each group was required to determine several different concepts for each subassembly/subproblem of their projects. They then evaluated each concept using a concept selection matrix, and the concept that ranked the highest was chosen for further development in the overall design. In most cases, this included a selection matrix to choose the best material to use for a given part. By the seventh week of the semester, each group submitted this information in the second chapter of their final report, as well as gave another presentation.

By the tenth week of the semester, the groups needed to have their final design completed and described in their third chapter, including engineering drawings, hand calculations, a preliminary budget, and a bill of materials. Once again, each group presented in front of the class. After their design was approved, they were allowed to begin ordering parts so that they could begin building. By the end of the semester, the students were expected to have their projects built and tested to ensure that all of the technical specifications set forth in Chapter 1 were satisfied. A final report was submitted, which included corrections/updates to the first three chapters, as well as a final chapter for results and conclusions. Chapter 4 included details verifying whether or not the technical specifications had been met; if one or more specifications were not met, the group needed to explain why, and what they would have done differently during the design process to prevent this shortcoming, or how they would fix the problem now if they had more time. A few groups did not complete their projects by the end of the semester, due to poor planning and/or ordered parts arriving too late in the semester. These groups were required to write a final chapter with detailed assembly instructions, such that their project could theoretically be completed at a future time by someone else. All groups gave a final presentation for their projects.

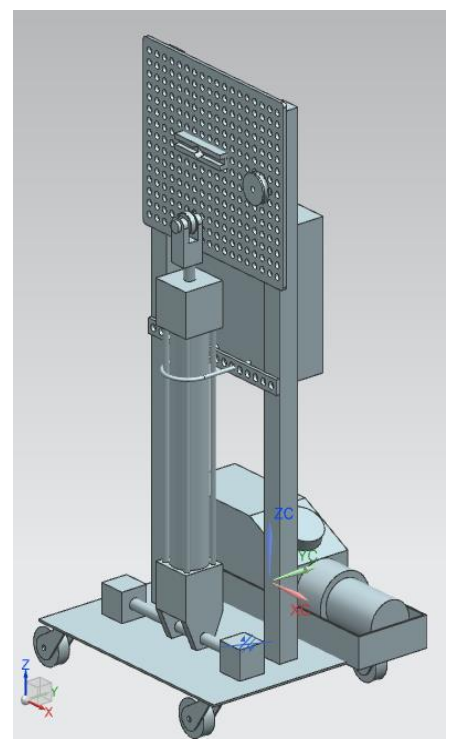

Figure 1: Rod bender

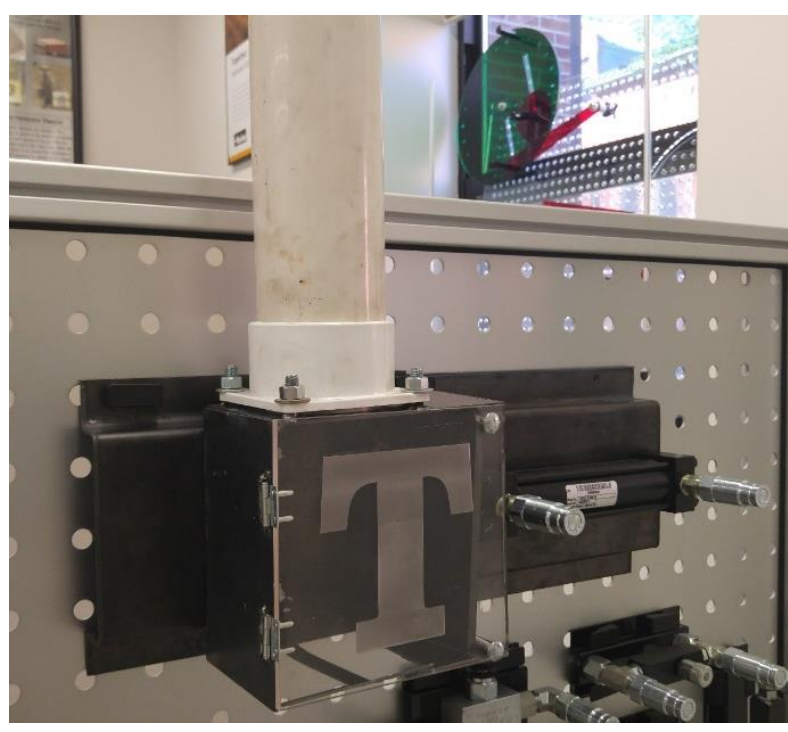

Figure 2: Hydraulic aluminum can smasher 


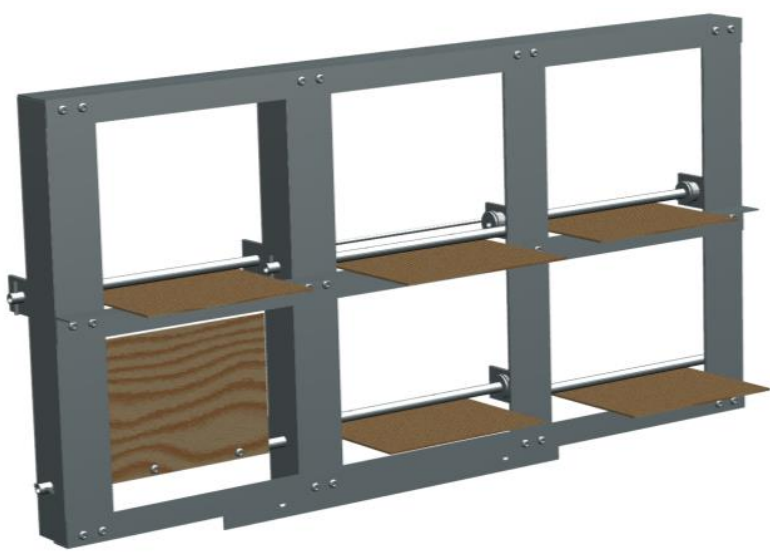

Figure 3: Nerf gun targeting system

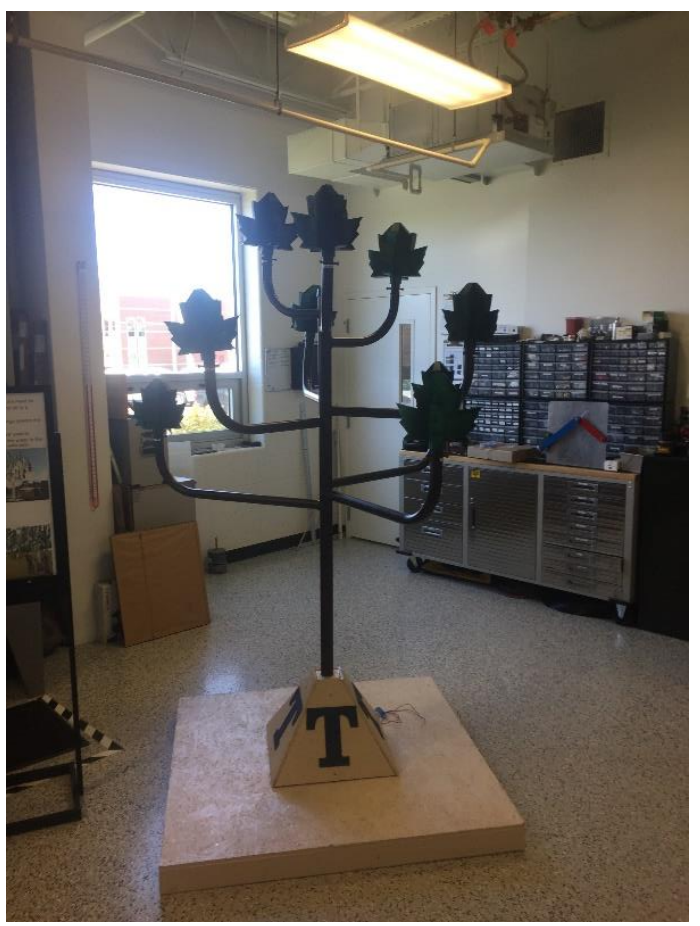

Figure 4: Wind turbine tree

Besides completing the semester long project, the students had weekly labs to complete during most weeks of the semester. The mechanical engineering lab technician conducted these weekly labs, assisted by the faculty member, who assigned and graded the lab reports. Each lab section was divided up into four groups of five students to complete the weekly labs and turn in one report per group. Some of these labs included green sand testing, sand casting, permanent mold casting, testing the mechanical properties of the castings made from the sand and permanent molds (tensile tests, hardness testing, and spectroscopy), sheet metal bending and welding to create a simple box, and demonstrations on how to operate various machines, such as the plasma cutter, laser cutter, lathe, and mill--the students needed to know how to use many of these machines so that they could use them to complete their final projects. In some cases, during the first hour of the weekly two hour lab time, half of the students would work in the lab with the lab technician, while the other half would be in a classroom with the faculty member to give their presentations; during the second hour, the two halves of the class would switch with each other. During the last four weeks of the semester, the students were permitted to spend the entire two hour lab period working on their final projects.

\section{Summary and Conclusions}

In summary, the large enrollment in the MP\&E Lab was handled by having the mechanical engineering lab technician co-teach the lab with a faculty member. The lab technician conducted the weekly lab experiments; developed most of the final projects for the students to choose from; and aided the students with practical building advice, running the various shop equipment, and approving and ordering materials/parts that the students requested. The faculty member provided students with design advice; help with their design calculations; graded project reports 
and presentations, as well as the lab reports; and generally tried to keep the student teams on schedule.

Although the logistics of the weekly labs were handled successfully, the final projects were less successful, with only about half of them fully completed and functioning as intended. According to the end-of-semester course evaluations, many students complained that their projects were too involved and time consuming for a one credit hour lab, or that their projects required in-depth knowledge of material from courses they had either not yet taken, or were taking at the same time, such as Solid Mechanics and Dynamics. In addition, some students who were working on projects meant to benefit the Grounds or Maintenance Departments stated that they felt like they were basically just providing free labor to the university. A few students in the class were seniors who had not been able to fit the MP\&E Lab into their schedule in earlier years. As such, they were also working on their senior design projects at the same time as the lab project. They expressed the feeling that the lab project was nearly as involved as a senior design project, but crammed into one semester instead of two. On the positive side, several students did express appreciation for the very hands-on nature of the course and the opportunity to learn how to use many of the tools and machines in the lab.

In light of the student feedback, in succeeding semesters the final projects have been reduced in scope, and more than two students are allowed in a group depending on the difficulty of the project. In many cases, projects that were not completed in one semester have been pushed forward to the next semester to be worked on and completed by another group of students, such as the iron dumper cart, wind turbine tree, aluminum can smasher, and building a small cast engine. According to the end-of-semester course evaluations, many students still complained about the workload being too great for a one credit hour lab. Others stated that there needed to be better communication between the faculty member and the lab technician regarding both the final project and weekly lab expectations. On a positive note, one student stated that "This class truly prepared me for senior design."

The current semester again has two sections of 20 students each. In a continuing effort to improve the course, each section has been divided into four equal groups, and each of the groups in a given section will be working on the same project, with a different project for each section. This arrangement is intended to alleviate the workload on the students by having larger group sizes, to avoid having any issues with one group feeling their project is more difficult than other projects, and with only two projects overall, to make the projects more manageable for the faculty member and lab technician to coordinate.

\section{References:}

[1] R. Hoadley and P. Rainey, A Manufacturing Processes Course for Mechanical Engineers, 2007 ASEE Annual Conference \& Exposition, Honolulu, Hawaii.

[2] J. Dillon, H. Henderson, and J. Butler, Popping the Top on Basic Machining Instruction, 2010 ASEE Annual Conference \& Exposition, Louisville, Kentucky. 
[3] D. Ramers, Integrating Manufacturing Projects into Mechanical Engineering Programs, 2002 ASEE Annual Conference, Montreal, Canada.

[4] M. Slifka, Active Learning Techniques for Engaging First Year Students in a Manufacturing Processes Course, 2010 ASEE Annual Conference \& Exposition, Louisville, Kentucky. 